\title{
Domestic Violence: A Hindrance to Optimal \\ Functioning of a Learner's Cognitive Capacity
}

\author{
Emily Ganga \\ Great Zimbabwe University, Faculty of Education \\ P.O. BOX 1235 Masvingo \\ E-mail: emilyganga@gmail.com
}

Kudzai Chinyoka

Great Zimbabwe University

E-mail: chinyokak@gmail.com

Moses Kufakunesu

Great Zimbabwe University

E-mail: moseskufakunesu@gmail.com

Accepted: September 24, 2012 Published: October 31, 2012

Doi:10.5296/ijld.v2i5.2599 URL: http://dx.doi.org/10.5296/ijld.v2i5.2599

\begin{abstract}
Domestic violence is a common phenomenon that seems to be taking a centre stage in hindering sustainable development in many homes today. Previously, advocates for peace within homes were concerned more about wives being beaten by their husbands, but today there is a shift in paradigm where wives are seemingly inflicting both physical and psychological pain on their husbands. As if this is not enough, the young boys and girls reared within these homes seem to be getting an equal share that resultantly impedes the optimal function of their cognitive capacities. This study analyses the various dimensions of domestic violence and the resultant impediment on the effective function of the learner's cognitive function. The study was structured from a constructivist learning perspective, bearing in mind three dimensional theoretical approaches covering the socio-cultural theory by Levy Vygotsky, ecological theory by Urie Bronfenbrenner and observational learning by Albert Bandura. The plight of the learner being nurtured within violent homes was surveyed where some teachers and pupils' observations, anecdotal records and vignettes were major data collection tools among young boys and girls randomly selected from both rural and urban schools locally. The study established that commitment by parents, caregivers and teachers in carrying out their responsibilities seem to be on the decline. The study further exposes some inherent challenges and abuses faced by learners in unsuitable living conditions. The implications of such
\end{abstract}


situations are that learning institutions should ascertain possible ways of liberating the affected learner and educate the parents, caregivers and teachers on the negative effects of perpetuating domestic violence.

Key Words: Domestic, Violence, Learning, Hindrance, Cognition.

\section{INTRODUCTION / BACKGROUND}

Domestic violence constitutes one of the most complex problems confronting many countries today. With the rising cost of living, the extent of the problem in Zimbabwe seems to be escalating. Reports of domestic violence fill many forms of the media each week. According to Musasa Project (2006), domestic violence entails the infliction of pain by a member of a family on a survivor. The survivor then lives in fear for their safety and their life. It can be regarded as any incident of threatening behaviour, violence or abuse between adults who have been intimate partners or family members regardless of gender or sexuality (Volpe, 2000).

According to Berns (2010:255), domestic violence can be defined as, "the systematic abuse by one person in an intimate relationship in order to control and dominate the partner". Violence in Zimbabwe is said to be rooted in Economic Structural Adjustment Programme (ESAP) that led to the retrenchment of more than 40000 people (Osirim, 2001). Many of these were family man or breadwinners. The majority failed to support their families resulting in failure for many man in fulfilling their gender roles. Violence began with just a slap on a wife from the husband/ breadwinner as means of relieving stress on economic matters. This filtered to children witnessing or being affected by the violence. The practice flourished with very few reporting the abuse. A slap from a husband was found to be normal in the African Culture for many decades (Armstrong, in Osirim, 2001). Thokozani Khupe, Deputy Prime Minister of Zimbabwe (2011) mentions that cases of domestic violence have been increasing at an alarming rate and that it remains the government's responsibility to act swiftly on the matter. She reiterates the fact that statistics are likely to be higher than before. So far, the Ministry of Woman's Affairs and Gender launched a programme aimed at removing stigma associated with domestic violence (DV) against woman and children. The prevalence seems to be high in all nations. For instance, Christian, Scribano, Seidi and Pinto-Martin (1997) established that children are advertent victims of violence between adults in the United States of America. They reviewed records of 139 children who reported at the emergency department with injuries from domestic violence. Their age ranged from 2-17 years with a mean score of 5 years. The most common injury was from being hit, 39\% attempted to intervene in parental disputes, $9 \%$ were hospitalised whilst $2 \%$ went into intensive care unit. And so, violence involving children is a world-wide issue. Prevalence may differ from country to country, but high in both developed and developing countries.

Victims of domestic violence usually suffer psychologically because they are not quite certain of when next violence would occur and affect them. Perpetrators of violence in the homes can be man or woman of any race, class, economic status and/ or religion. Zimbabwe categorises forms of family violence into physical, emotional, economic and sexual abuse. Berns (2010:255) claims that abusive relationships in the home can be physical, psychological, emotional or even sexual in nature. Hallahan and Kaufman's (2009) classification or forms of abuse in the United States is consistent with the classification utilised in Zimbabwe today. After some massive survey activities on domestic violence, Zimbabwe has recently passed on Act against domestic violence all in an effort to protect the less powerful members of the families like women and children. 
This paper strives to give an explicit discussion on how domestic violence hinders the optimal function of a learner's cognitive capacity. The learner referred to in this context is the child facing difficulties in an abusive and unstable home where it is assumed that learning should be taking place. Abused children are exceptional cases and should be of great concern to every citizen. This is because domestic violence is so abusive that it can lead to permanent neurological damage, other internal injuries, skeletal deformity, sensory impairment or even death. Chadwick (1989) also affirms that some psychological problems are usually inevitable outcomes of some forms of abuse. Domestic violence entails many criminal forms such as physical assault, sexual abuse, intimidation, economic deprivation and violent threats. Though many people talk about spousal violence, when it comes to domestic violence, this paper is concerned more about the child /learner facing the abusive predicament.

In an effort to define domestic violence, some authorities prescribe other names, such as 'intimate partner violence 'spouse abuse 'and 'family violence'. These include child abuse among other violent acts between family members. The Children and Family Court Advisory and Support Service Policy on domestic violence in U.K defines DV as a range of violent and abuse behaviours characterised by misuse of power and control by one person over another . Results of the violence are said to have profound consequences on lives of children and other individuals concerned. In concurrence, the Organic Law 1/2004 in Spain and the U.S office on Violence against Women (VW) redefined domestic violence as originating from positions of power of men over women. Women are supposed to the main care givers of the children and so if abused, the suffering is extended to the child/learner.

In Zimbabwe, domestic violence cuts across a wide range of sectors covering education, income, social status, race, religion, etc. Violence affects communication, problem solving and decision making in a society. It is not a construct that is accepted in any culture. For the child, it is said to have a detrimental effects on the child's health, growth, performance at school, interactions with other children and is detrimental to future adult life (a Freudian psychoanalytic perspective ).Most of the reports of violence the researchers observed and read about through the media seem to be occurring mainly in the homes. Research has confirmed that about $40-60 \%$ of man and women who abuse each other also abuse children. The 2005 World Health Organisation Multi-Country study on the magnitude of domestic violence reiterates the fact that it is somehow difficult to guide and monitor policy on issues of domestic violence in many countries. Hence, this study tries to elicit data on how far domestic violence can go in negatively influencing the cognitive capacity or learning of the child.

\section{THEORETICAL FRAMEWORK}

Many have gone a long way to try and view theories that help to explain causes of domestic violence. Included are psychological trait theorises as well as social theories that involve family structure stress and social learning. Characteristics and personality traits of the offender form part of the psychological theories that view issues of perpetrators self-esteem, impulsive acts and control as well as certain personality disorders. The social learning theory (Bandura, 1968) in Santrock (2009) sees domestic violence as emanating from observing and modelling other peoples' behaviour. As one vicariously observes reinforcements of certain violent behaviours at home or in society, he/she is likely to model it too. Such theorists see violence as cyclical moving from one generation to the next.

Other authorities explain domestic violence as arising from perceived need for power and control (Domestic Disturbance, 2001). Psychoanalysts would view violence as emanating from unresolved childhood conflicts (Freud, in Santrock, 2009). The need for power and control may be influenced by perpetrators own needs and inadequacies such as poverty, hostility, 
personality disorders, hereditary factors and social cultural factors or a combination of the causal factors.

Vygotsky socio-cultural theory asserts that culture is the prime determinant of an individual's development, where human beings are the only organisms seen to have created culture (Donald, Lazarus and Lolwana, 2010). Children learn as they interact with significant others and human cognition and learning occurs in social situations. Biehler and Snowman (2007:65) point out that according to Vygotsky, children learn more from instructional interactions that they encounter with those who are intellectually advanced, especially if the instruction is designed within the learner's zone of proximal development (ZPD). Berns (2010:236) views the zone of proximal development as, "Vygotsky's term for the space between what a learner can do independently and what he or she can do while participating with more capable others". Therefore, the theory informs readers that the process of learning takes place effectively when the child participates during interactions and he/she is allowed to internalise the social interactions. And so, the problem comes in when these social interactions are intermingled with situations of dysfunctional homes meant to be secure bases for the learner. Domestic violence disrupts the optimal function of a learner's cognitive capacity to an extent that it may leave the learner in a situation of total distress. Once this occurs, concentration around the learner`s usual ZPD is reduced or sometimes depleted. This is because the parents, siblings, peer and significant others, with whom children socialise and learn, fail to afford the opportunity to enhance learner's cognition due to disruptions resulting from domestic violence.

Donald, et al (2010:40) indicate that Urie Bronfenbrenner, through his ecological systems theory, brings in a socio-cultural view of human development by proposing five environmental systems based on fine-grained inputs of direct interactions with social agents combined with broad-based inputs of culture facilitate development of the learner. According to Johnson (2008:2), the five ecological systems encompass the micro-system(where the learner lives, for example, with family and peers ), mesosystem (referring to connections between microsystem or relations between family, school, peer, etc ), exosystem (experiences within the social settings), macrosystem (attitudes /ideologies of culture where one lives )and the chronosystem (as in the patterning of environmental events like parents' divorce ).

The theory endeavours to explain further Vygosktian viewpoints on culture and cognition. It is much more explicit in that it provides environmental tools that seem to either enhance or hinder cognitive development. For instance, in instances of domestic violence, a child's micro system or family becomes disturbed leading to further disturbance on his/her mesosystem (for example the home and school ). Further disruption on the exosystem (for example, a disrupted parents' work place) can easily affect the child at home and so this leads to total disturbance to a child's macro system (covering the larger cultural context).

Each of the systems institutes a bearing on the efforts to obtain high cognitive performance during learning. If the whole macro system faces situations of child abuse, spouse battering, economic deprivation, neglect and many other forms of violent situations, the learner living within such a system is grossly concerned. Bronfenbrenner's ecological systems theory concurs with Vygotsky (1978) theory on how a learner's culture can either enhance cognitive development or easily disrupt it. This study goes further to find out how disruptions through various forms of domestic violence can negatively affect the proper function of a child's cognitive capabilities.

Thirdly, Bandura`s Social learning Theory can also help to explain certain behaviours portrayed by children coming from violent backgrounds. In his Bobo doll experiments, 
Bandura $(1977,1978)$ proves the fact that both children and adults learn a great deal through observation and imitation (Lahey, 2009: 08). They, children, can learn many behaviours by from parents and other children. According to Bandura (1978 in February, 2006), children can learn traits such as industriousness, honesty, self-control, aggressiveness and impulsiveness through observations. In situations of domestic violence they can even imitate the hostile words from angry or fighting parents. Bandura emphasises fours factors leading to behaviour imitation namely; attention, retention, reproduction and motivation (Mwamwenda, 2004:186; Santrock, 2006; Skinner, 2009). A child is attentive as he/she watches, retains and learns the violent acts of behaviour. When circumstances become conducive enough, the child becomes motivated and imitates same behaviour. This is manifested in situations when adolescents provoke one another and eventually engages into a fight at home or even at school.

The three theories become the major informants of the study in because the three are societycentred and it is within the society that couples are found fighting, scolding, inducing fear and anxiety and abusing one another.

\section{THE STATEMENT OF THE PROBLEM}

The major research question of this study is as follows:

-How does domestic violence hinder the potential function of learner`s cognitive capacity?

From the major research question, some sub- problems were formulated as follows:

-Which are the various forms of domestic violence experienced by local learners?

-How does each form of violence hinder cognition of a learner/child?

-How can educators and other stakeholders emancipate the learner witnessing and getting involved in domestic violence?

\section{METHODOLOGY}

The study, falling within the qualitative paradigm, adopted a descriptive survey. Data were collected from 50 male and female in-service teachers (on block-release) whom the researchers assumed to have been carrying teacher's, parental and counselling roles in their respective schools. The 50 were taught Educational Psychology courses by the researchers at the time of this study. Gender distribution here was $60 \%$ for males and $40 \%$ for females because of the nature of enrolment at the time of this study. There were 30 male and 20 female in-service teachers of different age ranges. The lot of teachers were randomly selected from a population of 200 qualified primary and secondary teachers who were pursuing a Bachelors degree in Education at a local university. The teachers were recruited from various sections of the country`s provinces. They had had experience teaching in both rural and urban set ups.

In addition to the 50 teachers, twenty (20) purposefully selected school children (12 females and 8males) were also allowed to participate in the study`s focus group discussions based on their perceptions, witnessing and experiences of DV in dysfunctional homes. The researchers had an opportunity to involve the pupils whilst they were attending a peer educator`s workshop organised by a local non-governmental organisation (NGO) in town. The twenty (20) pupils had been picked up by their school authorities to represent their districts at the peer educators' workshop.

Regarding the issue of ethics, the researchers assured participants of strict confidentiality and that only pseudo names were to be used in presenting the results obtained. Participation was voluntary, and participants were offered the leeway to withdraw at any level of the study.

Data from both groups of participants (that is, 50 teachers and 20 learners $=70$ ) were merged to try and establish reality in as far as domestic violence deters optimal function of a learner`s 
cognition. Data from the teachers were collected through a questionnaire that comprised three sections with the first endeavouring to ascertain the form of domestic violence witnessed by teachers in their locality. The second section was related to how learners manifested the signs and symptoms of Domestic Violence (DV) in and outside the classrooms. The third section allowed teachers to explain how various forms of DV were affecting the assimilation and accommodation processes within the learner`s cognitive functioning. Open and close - ended questions formed the teacher's questionnaire. The administration of the questionnaires lasted a week. This was to allow them ample time to reflect on effects of DV and to allow them to complete the questionnaires fully within their busy schedules. This gave the researchers a $100 \%$ questionnaire return rate.

\section{RESULTS AND DISCUSSION}

Demographic details of participants showed that the teacher's group was made up of experienced school heads, senior teachers, counsellors and teachers without particular positions within their school set-ups. Their teaching experience ranged between five and 18 years, marking an experienced lot of classroom practitioners who provided authentic data on DV and cognitive function in learners.

The teachers narrated a list of aspects of domestic violence they had witnessed in various places where they were teaching. Issues constituting forms of DV were extracted from their responses as follows:

$$
\begin{aligned}
& \text {-physical assault } \\
& \text {-sexual abuse } \\
& \text {-neglect } \\
& \text {-emotional provocations } \\
& \text {-violent threats } \\
& \text {-economic deprivation } \\
& \text {-space deprivation } \\
& \text {-intimidation }
\end{aligned}
$$

Teachers also raised a number of responses that they had witnessed as signs and symptoms of effects of DV among their learners in their schools. Prevalence of responses ranged from common to very common.

\section{RESPONSES}

Variable

Common

\section{Very Common}

Retarded

concentration

span

Confusion

Self-blame

$*$

Flash

backs

*

Lowered

self

efficacy

Anxiety

over

recurrence

Exaggerated

startle

responses 
Intrusive

thoughts

A number of teachers indicated the fact that effects of DV on cognition actually begins during pregnancy and into childhood. Peedicayil et al (2004) in concurrence with Harner (2005) reiterate the fact that most prenatal visits to clinics are caused by DV. Teachers confirmed that delays in child development during pregnancy were as a result of disruptions due to DV. They seem to note developmental delays, stranger anxiety, regressive behaviours, excessive social involvement, mistrusting adults, poor personal hygiene, tiredness, irregular bowel habits and feelings of despair.

All these seem to occur in the homes where one parent abuses the other. One lady teacher wrote, 'If it is wife abuse, zvinonzwi mese nevana vako muri stupid 'implying the fact that, if the perpetrator is the husband, he is likely to also blame and abuse the children. The children then live in fear for their mother and also for themselves. Perhaps this is when children take self-blame simply because the family`s ecosystem is disturbed. Miller (2010) and Campbell (2010) also say that these observations indicate that a home with spouse abuse or DV is 15 times more likely to have child abuse.

Teachers also noted that children who respond to violence at home most of the time were on one of the extreme ends of the trait continuum- extraversion versus introversion. Where a child would show extreme introversion, the teachers added self isolation, irritability, poor problem-solving skills, low self-esteem, avoidance, lest the mishap or DV resurfaces.

As for extraverts, the teachers confirmed that the affected extravert usually prefers many social interactions with peer, plays truancy, show revenge seeking action and get involved in suicidal behaviours. Both abused extraverts and introverts that witnessed DV were said to be filled with phobias, sometimes showed Post Traumatic Stress Disorder (PTSD) and were generally not settled. This is in line with observations made in studies of DV effects by Newton (2001), Terr (1991) and Volpe (2000). They were said to be lacking a good concentration span in classroom activities.

In an effort to establish authentic data from the sample, the researchers involved the children in a focus group discussion where perceptions and views of children on DV effects and on cognition were unveiled. In concurrence to teachers observations, the children mumbled many such responses as we quote" Handichatonyatsodzidza zvakanaka ndikarangarira zvandinoona month end yoga-yoga" (I am unable to concentrate if I recall what I witness every month end).In other words there seemed to be certain times of the month when DV is rampant in some homes. In this particular case, DV could be caused by the insufficient family income at month end.

Another learner, pseudo named Tukai, also said "Kutukana kwavanoita vachimanyidzana mumugwagwa zvinotinyadzisa sevana, zvakare zvinoita kuti ndirege kudzidza zvakanaka kuchikoro." (The manner in which they scold and chase after one another in the streets makes me feel ashamed and stigmatised as well as making me fail to concentrate on learning at school).

A third response from a learner pseudo name, Mhanya, indicated that when parents fight children become frightened and that no one is able to stop the violence."Zvinotyisa zvekuti kana vatanga kurwa hapana anovanunura, "meaning the DV is so horrifying that when they (parents) start it up no one is able to stop them.

The researchers noted with great interest that as they discussed more violence situations with the children, they did not want to attach their own parents into the violent situations. Instead, they placed the DV occurrences on dysfunctional neighbouring families. The issue of protecting family dignity remains an African culture and many may not open up for resechers especially in very sensitive issues such as DV. And so, the researchers respected this defence 
mechanism and concentrated on the main purposes of the study which was to find out how DV affected cognitive function of learners. Meichenbaum (2004) in concurrence with Stannard (2009) confirms some of the effects of DV on cognition adding on other emotional and behavioural responses as follows; shock, terror, guilt, horror, irritability, anxiety, hostility, dipression, avoidance, social withdrawal, interpersonal stress, substance abuse and delinquency. This leads to possible school dropouts and eventually hopelessness in and outside the home and school.

Responding to the question on witnessing DV, both teachers and pupils agreed that DV hindered learning to a great extent, it seemed it gets worse in situations of severe poverty, loose family ties or ecosystems, low education level of primary care giver. Fantuzzo, Boruch, Akins and Marcus (1997) and Imhonde, Oyaziwo and Oboite (2009) confirm this view. The children echoed saying that the closer one is to the DV situation, the greater the effect on the observer. It becomes more painful when one is emotionally close to the victim. On this issue, children related stories of DV that they had read about in the media lamenting how they felt and empathised with other children whose mother would have been murdered. Witnessing violence between one strong member and a weaker victim is an insidious event to all children. Maugham and Cicchetti (2000) and Baker et al (2002) affirm that DV affects a child cognitive adjustment leaving him or her in a helpless predicament. Stakeholders and the government need to keep a closer look at the roots and effects of DV. The question is 'What is the way forward?

Zimbabwe has two non-governmental organisations (NGO) trying to address the issue of DV.These are Musasa project and the Zimbabwe Resource Centre and Network. However, there seem to be an increase in the number of DV reports in the local media, which necessitates the need for both educators and parents to join hands and establish best ways of resolving the crises.

\section{CONCLUSIONS:}

Basing on the presented findings and discussion, the following conclusions were debuted; -DV deters proper cognitive function in both children and adults. The effects are detrimental to a child's problem- solving skills and other cognitive processes.

-Children are affected by DV in a variety of ways. The majority of children who reside in violent homes are at risk and effects vary from child to child.

-Most children who witness and try to intervene in spousal DV end up getting physically abused by their care givers.

-Direct exposure to DV affects child adjustments because it disrupts parenting practices or relationships between parents and their children.

-Besides changes in behaviour, school performance may decline and the child usually complains of a number of discomforts such as headaches, diarrhoea, etc.

-Children's attention span is distorted by the need to rescue victims of DV and at the same time keeping the DV a family secret. Children from violent homes are sometimes stigmatised by their peers.

-Observing DV on their own parents causes trauma that may become severe enough to get to Post-Traumatic Stress Disorder (PTSD). This is a situation where a counselling psychologist may be required to save the learner especially on academic problems and poor functioning as stated by Terr (1991). The authority confirms that PTSD in type 1 has short term effects whilst type 2 has long term effects caused by prolonged abuse and chronic victimisation. Therefore, early intervention is ideal. 


\section{RECOMMENDATIONS}

The following recommendations were drawn from the given findings and conclusions

: -The cognitive capacity of a learner`s mind (i.e. the process of assimilation, accommodation and equilibration) is functional when home is peaceful. Therefore, parents should try and iron out differences amicably without causing direct or indirect harm to the helpless minor/ child/learner.

-Care-givers should make note of early and amendable stages in the development of Domestic Violence. Major damages can be prevented if proper communication channels are followed by parenting couples.

-Both parents and educators should watch out for signs and symptoms of abuse emanating from DV. Early intervention by school counsellors and/or psychologists, in the form of guidance and counselling, is a necessity to help learners cope with effects of DV.

-School administrators should allow individual and group counselling on issues of DV so that children may open for help from therapist and concerned adults.

-Teachers should allow learners to express their feelings in the best way possible, for example, through writing, painting, toy usage in younger children and verbalising in older children.

-Every teacher/ parent is a counsellor on issues of DV and so should give guidance to parents and affected children appropriately. Teachers and parents should be good role models of family life.

-Where possible, family members should engage in family counselling with an experienced therapist. Counselling of children should help to restore their self-efficacy

-Members of the community should inform the Police about DV cases as a means of safeguarding children in dysfunctional homes. Perpetrators of emotional abuse should be reprimanded or should be put to book early before they cause more harm.

- Non- governmental Organisations (NGOs) that offer to safeguard woman should look into the plight of children living within violent homes. Train the child or the victim in assertive skills. - Like other Human Rights, The Convention on the Rights of the Child should be respected by every citizen.

-Free communication services in the form of free telephone lines offered by Child line -Zimbabwe should be passed on to suffering children even in the rural areas. These allow the children to contact security in cases of emergency. 


\section{REFERENCES}

Baker, L. L. Jaffee, P.G. and Ashboume, L. 2002 Child exposed to domestic violence available on http:/www.ifc.on.ca/ece-us.pdf

Bandura, A. 1977 Social learning theory Englewood Cliffs: New York. Prentice Hall

Bandura, A. 1978, in February, 2006 Social learning theory of aggression. Journal of Communication (on line publication) 28, issue (3) 12-29

Beihler, R. F. and Snowman, J. 2003 Psychology applied to teaching Boston: Houghton Muffling

Berns, R.M. 2010 Child, Family, School, Community: Socialisation and Support (Eighth Edition) London, Wadsworth Cengage Learning

$\begin{array}{llll}\text { Campbell, } & \text { J. } & 2010 & \text { Parentification }\end{array}$ http:charactertherapist.blogs.pot.com2010/06/13-parentificationhtml

Christian, Scribano, Said and Pinto- Martin 1997, 2004 Domestic violence and children: Effects of domestic violence on children available on http://www.medscape.com/view article/50829123

Donald, D., Lazarus, S. and Lolwana, P.2010 Educational Psychology in Social Context: Ecosystemic Applications in Southern Africa (4 ${ }^{\text {th }}$ Edition). Cape Town, Oxford University Press Southern Africa (Pty) Ltd

Edleson, J . L. Ellerton, A .L. Segre, A.E. Kirchbreg, S O. and Ambrose, A,T 2007 Assessing Child Exposure to Adult Domestic Violence Children and Youth Services Review 29 (7) 961-971, Link text

Frantuzzo, J. W. Boruch Akins, A. and Maraus, S. 1997 Domestic Violence and Children Prevalence and Risk in 5 Major US Cities. Journal of the American Academy of Child and Adolescent Psychiatry, 36, 116-122

Hallahan, D.P. Kaufman, J.M. and Parton, P. 2009 Exceptional learners: Introduction to special education ( $11^{\text {th }}$ Eds) Boston \& Alyn \& Bacon

Harner, G. 2005 Domestic Violence and Children: Effects of Domestic Violence on Children. Journal of Paediatric Health Care 19 (14) 206- 212

Imhonde, H. Oyaziwo, A. and Oboite, W. 2009 Domestic Violence and Adolescents Psychological Functioning Among Secondary School Students in Benin Metropolis of Nigeria: European Journal of Educational Studies 1 (1) 2009

Johnson, E. S. 2008 Ecological Systems and Complexity Theory: Toward an Alternative Model of Accountability in Education. Complicity: An International Journal of Complexity and Education 5(1) 1-10

Lahey, B.B. 2009 Psychology: An Introduction (10th Edition) New York: McGraw-Hill Higher Education

Meichenbaum, D. 1994 A Clinical Handbook/Therapist manual for assessing and treating Adults with Post Traumatic Stress Disorder. Ontario, Canada, Institute Press. 
Miller, D.2010 Children's Exposure to Violence on Children-Community Violence available on http://education .stateuniversity.com/pages/2531Violence-Exposure-htm

Musasa Project September, 2006 Training manual on Gender-Based Violence, Harare: Nisaa Institute of Women's Development

Mwamwenda, T.S. 2004 Educational Psychology: An African Perspective. Cape Town : Heinemann Publishers

Newton, C. J. February, 2001 Domestic Violence: An Overview: Mental Health Journal in Counselling.com

Osirim, M. J. 2001 Crisis in the State and Family: Violence against Women in Zimbabwe. Women Studies International Journal

Peedicayil, A. Sodowski, L. S. Shankar, V. Jain, D. and Suresh, S. July, 2004 Spousal physical Violence against women during Pregnancy. International Journal of Obstetrics and Gynaecology Volume 111 (7) 682-687

Santrock J, W. 2009 Life-Span Development. New York: McGraw-Hill

Skinner, C. 2009 Educational Psychology (4 ${ }^{\text {th }}$ Eds) New Delhi: PH Learning Pvt. Ltd

Stannard, L. 2009 Emotional Effects of Domestic Violence on Children. available on http://www.livestrong.com/article 18332-emotinal-effects-domestic-violence-children

Terr ,1991 Childhood trauma: An Outline and Overview. American Journal of Psychiatry, $148,10-20$

Volpe, J. S.2000 Effects of Domestic Violence on Children and Adolescents: An Overview of American Academy of Experts in Trauma Stress: Inc

Vygotsky, L. 1978 Interactions between Learning and Development. From mind and $\begin{array}{lllll}\text { society } & \text { pp.79-91.Cambridge, } & M & \text { A: } & \text { Harvard }\end{array}$ http://www.psy.cmu.edu/-siegler/vygotsky78.pdf

\section{ABOUT THE AUTHORS:}

Ganga Emily, Chinyoka Kudzai and Kufakunesu, Moses are lecturers in Educational Psychology at Great Zimbabwe University within the Faculty of Education. The trio are pursuing doctoral studies in Psychology of Education with the University of South Africa (UNISA). Their research interests are in Learning of children, Child and Adolescent Development, Issues in Poverty and HIV/AIDS. 